\title{
Metal hydride based thermal energy storage system requirements for high performance concentrating solar power plants
}

Claudio Corgnale*, Bruce Hardy, Theodore Motyka, Ragaiy Zidan

\begin{abstract}
High temperature concentrating solar power plants require suitable thermal energy storage systems to produce electric power efficiently. Thermochemical energy storage based on metal hydrides represents a very appealing prospect for low cost and high efficient solar storage systems. The objective of the paper is to assess the properties required by the metal hydride systems to achieve the U.S. Department of Energy's SunShot techno-economic targets. A simplified model has been developed to evaluate the cost and the exergetic efficiency of hydridebased storage systems. Results demonstrate that metal hydride materials, operating at temperatures higher than $650{ }^{\circ} \mathrm{C}$, with reaction enthalpy on the order of $95-110 \mathrm{~kJ} / \mathrm{molH}_{2}$, raw material cost on the order of $1.4-2 \$ / \mathrm{kg}$, weight capacities on the order of $3-4 \%$ and operating pressures on the order of tens of bars have the potential to closely approach the targets. Selected sensitivity analyses have also been carried out showing that the raw material cost, the material weight capacity and the metal hydride reaction enthalpy are the properties that strongly affect the performance of the storage system.
\end{abstract}




\section{Nomenclature}
$\mathrm{A}=\quad$ Heat transfer area $\left(\mathrm{m}^{2}\right)$
$\mathrm{C}_{\mathrm{HE}}=\quad$ Heat transfer system installed cost $(\$)$
$\mathrm{C}_{\mathrm{M}}=\quad$ Metal hydride material installed cost $(\$)$
$\mathrm{C}_{\mathrm{PV}}=\quad$ Pressure vessel (wall) $\operatorname{cost}(\$)$
$\mathrm{C}_{\mathrm{R}}=\quad$ Cost of the raw metal hydride material (\$)
Cs $=\quad$ TES system specific cost $(\$ / \mathrm{kWhth})$
$\mathrm{CSP}=\quad$ Concentrating Solar Power
$D_{\text {in }}=\quad$ Heat transfer fluid tube diameter (Figure 2) (m)
$\mathrm{D}_{\text {out }}=\quad$ Single metal hydride structure diameter (Figure 2) $(\mathrm{m})$
DOE $=\quad$ U.S. Department of Energy
$\mathrm{DOF}=\quad$ Degree of freedom
$\mathrm{D}_{\text {vessel }}=\quad$ Internal vessel diameter $(\mathrm{m})$
Ech $=\quad$ Chemical exergy content $(\mathrm{kJ})$
$\mathrm{ENG}=\quad$ Expanded Natural Graphite
$\mathrm{E}_{\mathrm{th}}=\quad$ Thermal energy stored (kWhth)
$E t h=\quad$ Thermal exergy content $(\mathrm{kJ})$
$\mathrm{h}=\quad$ Specific enthalpy $(\mathrm{kJ} / \mathrm{kg})$
$\mathrm{HE}=\quad$ Heat exchanger 


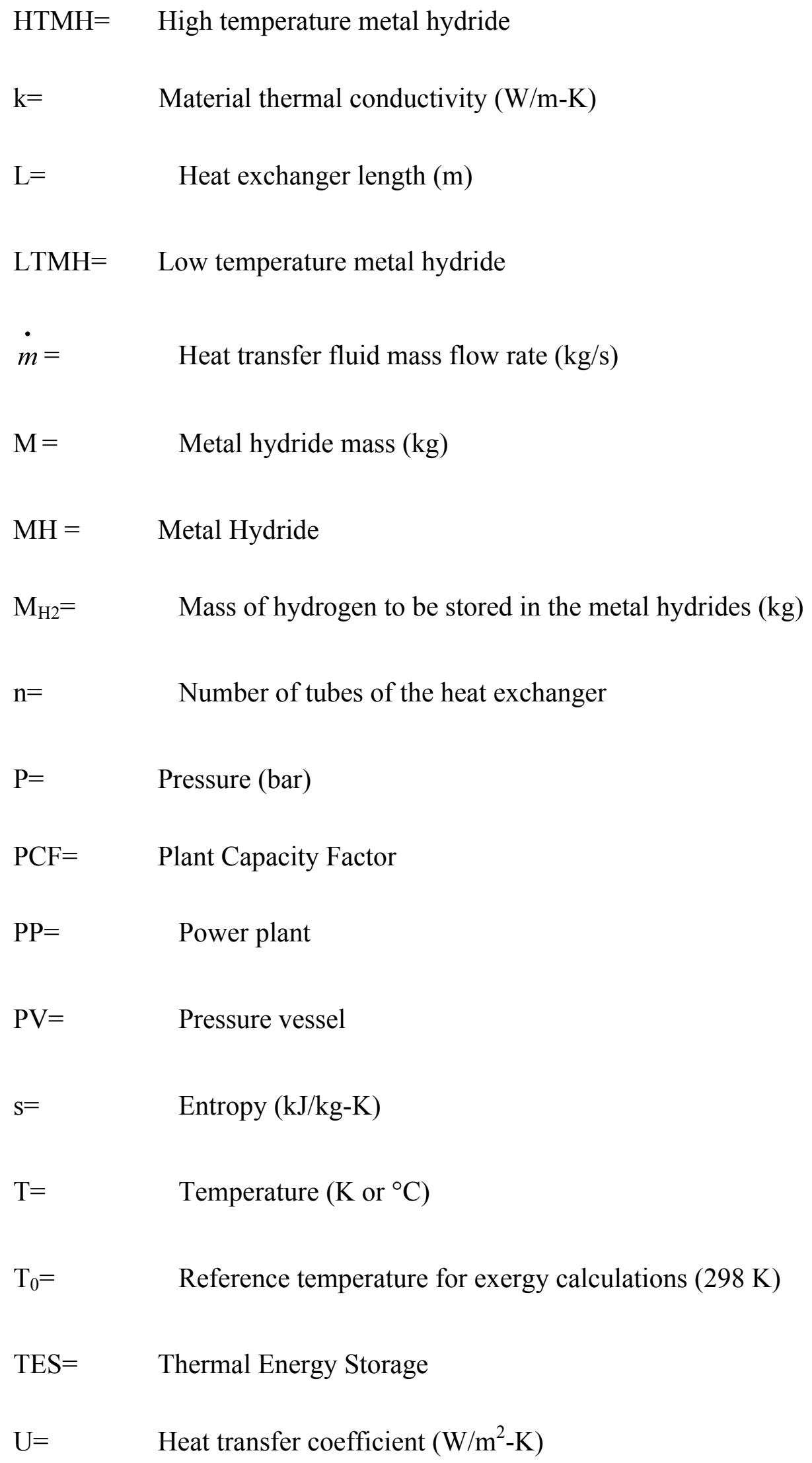




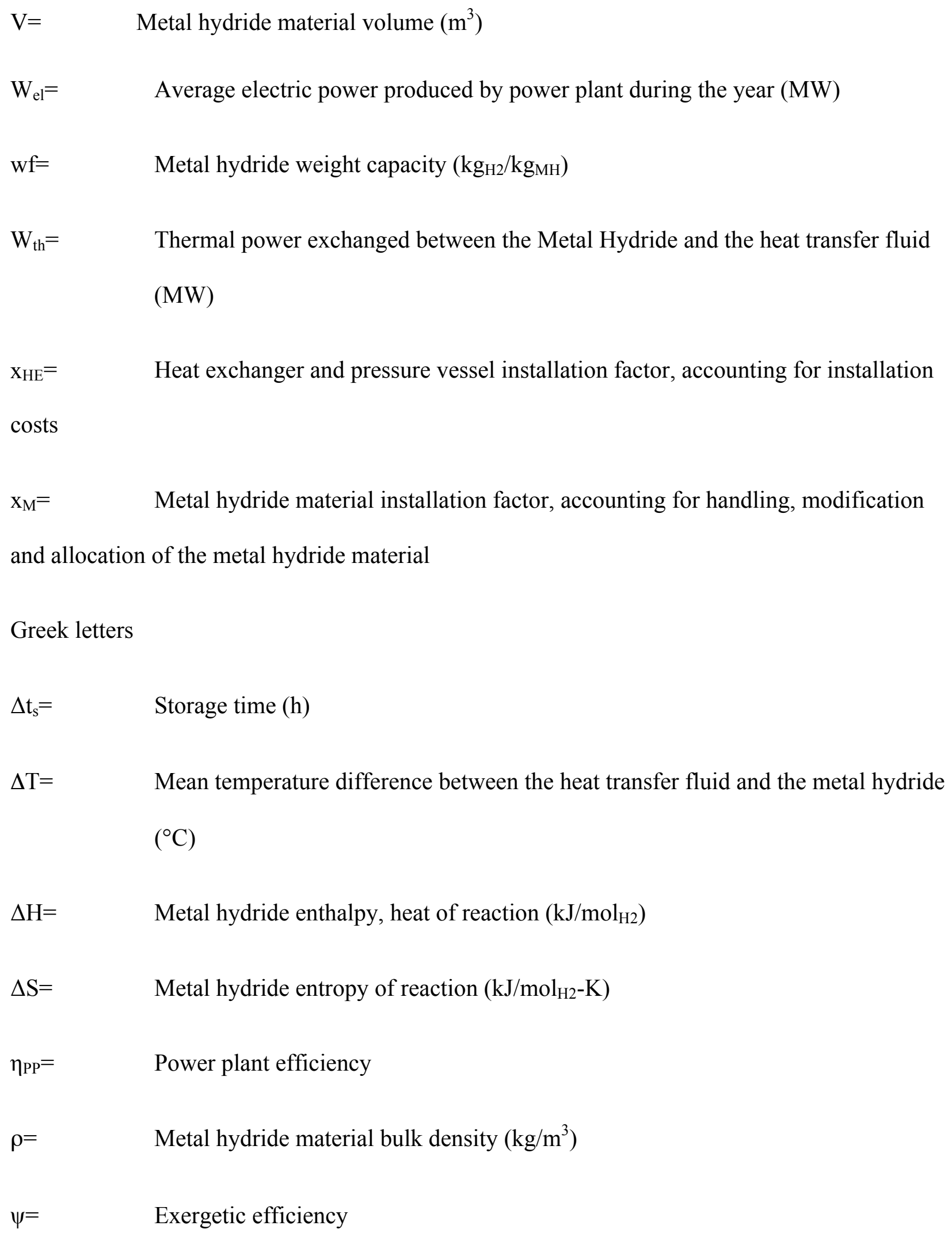




\begin{tabular}{|c|c|}
\hline Subscripts & \\
\hline $\mathrm{ic}=$ & Property referred to station ic (inlet during charging) as shown in Figure 3 \\
\hline $\mathrm{id}=$ & Property referred to station id (inlet during discharging) as shown in Figure 3 \\
\hline $\mathrm{oc}=$ & Property referred to station oc (outlet during charging) as shownin Figure 3 \\
\hline $\mathrm{od}=$ & Property referred to station od (outlet during discharging) as shownin Figure 3 \\
\hline $\mathrm{c}=$ & Referred to the charging process \\
\hline cond $=$ & Heat transfer coefficient referred to conductive heat transfer process \\
\hline $\operatorname{conv}=$ & Heat transfer coefficient referred to convective heat transfer process \\
\hline $\mathrm{d}=$ & Referred to the discharging process \\
\hline $\mathrm{HTMH}=$ & High temperature metal hydride \\
\hline $\mathrm{LTMH}=$ & Low temperature metal hydride \\
\hline $\mathrm{S}=$ & Shell side \\
\hline $\mathrm{T}=$ & Tube side \\
\hline
\end{tabular}

\section{INTRODUCTION}

Renewable source driven power plants are one of the most attractive options to produce electricity without local greenhouse gas emissions. Among these plants, CSP systems represent 
one of the most realistic options, mainly because it is possible to produce highly dispatchable electric power at high efficiencies and low costs $[1,2]$. However only CSP plants equipped with TES systems can compete economically with traditional fossil fuel plants to provide a stable energy resource that optimizes grid utilization [3-5]. Three types of TES systems are principally being developed today. They can store thermal energy as: (1) sensible heat (e.g. molten salts with no phase change), or (2) latent heat (i.e. phase change materials), or (3) thermochemical heat (i.e. through chemical reactions occurring in the materials).

Among the thermochemical systems, those using $\mathrm{MH}$ materials are unique, due to their high energy densities, reversibility and potential for low cost and high exergetic efficiency [6]. TES systems based on Li compounds were among the first MH systems investigated to store thermal energy at high temperatures. One application of Li-based TES systems integrated the TES with a solar parabolic concentrator plant for both solar power plants and for satellite applications [7]. The concept was demonstrated to perform adequately for long operating times [7], but the high cost of the Li material made the system unfeasible for low-cost, solar driven power plants. More recently, attention has shifted to $\mathrm{Mg}$ based hydrides for high temperature solar driven systems. This is mainly due to the lower cost of magnesium relative to lithium. Several studies were carried out on Mg-based MH materials, examining the behavior of such systems to store heat at temperatures ranging from 400 to $500{ }^{\circ} \mathrm{C}$. The materials showed gravimetric energy densities in the range of 2160 to $2520 \mathrm{~kJ} / \mathrm{kgMg}$ [8], which are about 10 times higher than those of current molten salt systems [6]. Additional studies were also carried out comparing $\mathrm{Mg}-\mathrm{Fe}, \mathrm{Mg}-\mathrm{Ni}$ and Mg-Co compounds, identifying Mg-Fe as the most promising compound in terms of economic performance and operating conditions [9]. Other studies have been carried out on systems based on Na-Mg compounds for high temperature heat storage applications (on the order of 500-600 
$\left.{ }^{\circ} \mathrm{C}\right)$. These compounds demonstrated good performance under different operating conditions [10]. Recent studies have been performed to demonstrate the feasibility of a newly developed $\mathrm{Na}-\mathrm{Mg}$ based material (namely $\mathrm{NaMgH}_{2} \mathrm{~F}$ ) as a high temperature and high performance hydride for TES applications $[11,12]$. When compared to $\mathrm{NaMgH}_{3}$ hydride, $\mathrm{NaMgH}_{2} \mathrm{~F}$ material showed higher stability and higher operating temperatures (on the order of $550-650^{\circ} \mathrm{C}$ ). In addition, the $\mathrm{NaMgH}_{2} \mathrm{~F}$ material system demonstrated the capability to reach lower system cost (approximately $30 \$ / \mathrm{kWhth}$ ) and higher exergetic efficiency (about 86\%) [11,12]. The material still needs additional research and development in order to improve its cycling ability at the temperatures of interest [12]. In order to examine higher temperature systems, several studies have also been conducted on Ti and Ca based hydrides as potential TES materials operating at very high temperatures $\left(\geq 700^{\circ} \mathrm{C}\right)$ and low pressures $(<5$ bar $)[6,13]$. However, these materials show specific techno-economic limitations mainly due to the coupled MH material's high cost (for the Ti based $\mathrm{MH}$ ) and due to severe corrosion issues (for the $\mathrm{Ca} \mathrm{MH}$ ).

A comprehensive screening analysis of existing MH-based TES systems against the technoeconomic targets indicated in the DOE's SunShot Initiative [14,15] has recently been carried out and reported in Reference [6]. The targets refer to the installed cost of the system ( $\leq 15 \$ / \mathrm{kWhth})$, the exergetic efficiency of the TES ( $\geq 95 \%)$, the operating temperature $\left(\geq 650^{\circ} \mathrm{C}\right)$ and the volumetric energy density ( $\geq 25 \mathrm{kWhth} / \mathrm{m}^{3}$ ). The study demonstrated that among the currently available MH's, several materials have the potential to meet and often exceed some of the targets. However, none of the presently available MH based TES systems can meet all the targets. Therefore, additional research and development is required, including (but not limited to) MH material and system development, heat transfer system enhancement and pressure vessel cost reduction. The aim of this paper is to define the properties required by the ideal $\mathrm{MH}$ 
materials (referred to as the MH materials that allow the TES system to meet the DOE SunShot targets), as well as the improvements the current $\mathrm{MH}$ systems need to achieve the targets.

Techno-economic models, already developed for the application reported in Reference [6], have been suitably modified to evaluate the installed cost and the exergetic efficiency of the overall TES system. The data, the unknown quantities and the DOF's involved in the problem, which represent the inputs and outputs of the models, have been identified and assessed. The results are discussed in the paper showing: (1) the properties of the ideal MH materials, (2) the performance gap between the ideal MH system and the available material systems, and (3) TES improvements (MH material modifications, heat exchanger modification, etc.) needed to achieve the ideal $\mathrm{MH}$ performance (i.e. DOE targets). Selected sensitivity analyses were also carried out to evaluate the sensitivity of the system performance to the most influencing and distinguishing parameters and material properties.

\section{The Metal Hydride-based thermal energy storage system}

The solar plant, shown in Figure 1, is comprised of a solar capturing and concentrating section, the TES section and the power plant. The TES section utilizes metal hydrides to store heat via hydrogen based chemical reactions.

\section{$\{$ Figure 1$\}$}

The power plant operates throughout the day at working conditions and electric power level ("Electricity out" in Figure 1) defined by the nominal power and the PCF that mainly depends on the storage time and the location of the plant. The main power cycles, being considered for integration into solar plants, are the steam Hirn cycle (or the supercritical steam cycle) and the 
supercritical $\mathrm{CO}_{2}$ Brayton cycle [16]. The steam cycle works at temperatures on the order of 500$650^{\circ} \mathrm{C}$, depending on the operating pressure and typology of the plant, while the gas turbine plant usually requires temperatures on the order of at least $650-700{ }^{\circ} \mathrm{C}$ or higher [16]. The storage system shown in Figure 1 is comprised of two MH materials operating at two different temperatures and having two different chemical reaction enthalpies. Its working principles are described in the following.

During the day when enough direct solar heat is available, the power plant is driven directly by solar heat and the available surplus solar power is stored in the TES. The storage system stores heat at high temperature shown as "Heat In" in the "HT metal hydride" in Figure 1. The solar radiation heats the HTMH releasing the hydrogen to the LTMH. The HTMH works at high temperature and has high reaction enthalpy, allowing it to capture and transfer a large amount of heat, through the release of hydrogen to the LTMH (endothermic process). The hydrogen pressure in the HTMH increases and the gas flows into the LTMH. The LTMH absorbs hydrogen (exothermic process) and releases low temperature heat. The heat is extracted from the TES system, shown as "Heat Out" from the "LT metal hydride" in Figure 1. During the night or at times when additional thermal power is needed to run the power plant, the process is reversed. Hydrogen flows to the HTMH from the LTMH, which releases hydrogen after exchanging low temperature external heat shown as "Heat In" in the "LT metal hydride" in Figure 1. The hydrogen moves back and is absorbed by the HTMH exothermally, providing the needed high temperature heat to the power plant shown as "Heat Out" from the "HT metal hydride" in Figure 1. The hydrogen is shuttled between the two-hydride beds through suitable thermal management of the TES units and choosing suitable and effective material pairs. Using only small pressure changes, hydrogen can be transferred from one metal hydride to another to exchange the required 
heat with the external heat transfer fluid. The TES is able to operate as a self-sustaining system without using mechanical compressors that would make the system more expensive and more complex to manage. The sensible heat associated with the hydrogen flowing between the HTMH and the LTMH is recovered assuming a well-insulated piping connection system and including a small, inexpensive regenerative material system that recovers the sensible heat of the hydrogen flow. The energy density that can be provided by the use of metal hydride systems has been shown to be on the order of 15-20 times higher than molten salts-based TES systems and about 5-10 times higher than phase change materials $[13,6]$. This can substantially reduce the size and the capital cost of many CSP TES systems.

\section{The MH system techno-economic model}

The DOE released specific technical targets for the CSP TES systems [14,15], reported here:

- TES operating temperatures higher than $650{ }^{\circ} \mathrm{C}$ to assure high efficiencies of the power plant,

- TES exergetic efficiency higher than $95 \%$,

- TES specific (installed) cost lower than $15 \$ / \mathrm{kWhth}$, and

- TES volumetric energy density higher than $25 \mathrm{kWhth} / \mathrm{m}^{3}$.

A simplified basic techno-economic system model has been set up with the aim of defining the properties of the ideal MH material-based TES. The ideal TES system uses MH materials that allow the TES system to meet the targets in terms of specific cost, exergetic efficiency, volumetric energy density and working temperatures. The data, unknowns and DOF's involved in the system techno-economic analysis have been identified and assessed as discussed in the following sections. 


\subsection{The system economic model}

The specific installed cost of the TES system, Cs (\$/kWhth), has been assessed accounting for: (1) the cost of the $\mathrm{MH}$ materials $\left(\mathrm{C}_{\mathrm{M}}\right),(2)$ the cost of the heat transfer system $\left(\mathrm{C}_{\mathrm{HE}}\right)$, (3) the cost of the pressure vessel $\left(\mathrm{C}_{\mathrm{PV}}\right)$, as shown in Equation 1:

$$
\mathrm{Cs}=\left(\mathrm{C}_{\mathrm{M}}+\mathrm{C}_{\mathrm{HE}}+\mathrm{C}_{\mathrm{PV}}\right) / \mathrm{E}_{\mathrm{th}}
$$

The explicit relationship between the overall thermal energy stored in the TES system $\left(\mathrm{E}_{\mathrm{th}}\right)$ and the solar plant properties is given in the Annex. $\mathrm{E}_{\mathrm{th}}$ is a function of the plant properties as expressed in Equation 2:

$$
\mathrm{E}_{\mathrm{th}}=\mathrm{E}_{\mathrm{th}}\left(\mathrm{W}_{\mathrm{el}}, \Delta \mathrm{t}_{\mathrm{s}}, \eta_{\mathrm{PP}}, \mathrm{PCF}\right)
$$

The installed cost of the $\mathrm{MH}$ material $\left(\mathrm{C}_{\mathrm{M}}\right)$ is given by:

$$
\mathrm{C}_{\mathrm{M}}=\left(\mathrm{C}_{\mathrm{RHTMH}} \mathrm{M}_{\mathrm{HTMH}}+\mathrm{C}_{\mathrm{RLTMH}} \mathrm{M}_{\mathrm{LTMH}}\right)\left(1+\mathrm{x}_{\mathrm{M}}\right)
$$

The value of the first term in parenthesis is based on the raw cost of the materials. This cost is given by the specific cost (in terms of $\$ / \mathrm{kg}$ ) of the raw HTMH and LTMH materials $\left(\mathrm{C}_{\mathrm{RHTMH}}\right.$ and $\left.\mathrm{C}_{\mathrm{RLTMH}}\right)$ multiplied by the mass of metal hydrides $\left(\mathrm{M}_{\mathrm{HTMH}}\right.$ and $\left.\mathrm{M}_{\mathrm{LTMH}}\right)$. The second term $\left(1+\mathrm{x}_{\mathrm{M}}\right)$ accounts for all the additional manufacturing, work and handling cost needed to locate and accommodate the MH materials inside the tank ${ }^{\dagger}$.

\footnotetext{
${ }^{\dagger}$ The additional MH material cost has been assumed as the same percentage of the raw material cost for both the HTMH and the LTMH systems. This assumption is reasonable based on the raw material cost data of the identified 'ideal' MH materials.
} 
The explicit relationships of the terms $\mathrm{M}_{\text {Hтмн }}$ and $\mathrm{M}_{\mathrm{LTMH}}$ are reported in the Annex. They can be expressed as a function of the plant properties $\left(\mathrm{W}_{\mathrm{el}}, \Delta \mathrm{t}_{\mathrm{s}}, \eta_{\mathrm{PP}}, \mathrm{PCF}\right)$ and material thermodynamic and structural properties $\left(\Delta \mathrm{H}_{\mathrm{HTMH}}, \mathrm{wf}_{\mathrm{HTMH}}, \mathrm{wf}_{\mathrm{LTMH}}\right)$ as described in Equations 4 and 5:

$$
\begin{aligned}
& M_{\text {HTMH }}=M_{\text {HTMH }}\left(\mathrm{W}_{\mathrm{el}}, \Delta \mathrm{t}_{\mathrm{s}}, \eta_{\mathrm{PP}}, \mathrm{PCF}, \Delta \mathrm{H}_{\mathrm{HTMH}}, \mathrm{wf}_{\mathrm{HTMH}}\right)^{\ddagger} \\
& \mathrm{M}_{\text {LTMH }}=\mathrm{M}_{\mathrm{LTMH}}\left(\mathrm{W}_{\mathrm{el}}, \Delta \mathrm{t}_{\mathrm{s}}, \eta_{\mathrm{PP}}, \text { PCF }, \Delta \mathrm{H}_{\mathrm{HTMH}}, \mathrm{wf}_{\mathrm{LTMH}}\right)
\end{aligned}
$$

The cost of the heat transfer system (the second term in Equation 1) has been assessed assuming the shell and tube heat exchanger concept as the baseline approach. This assumption is based on the fact that the shell and tube concept is a well-known technology that allows for possible future improvements as well. The MH bed has been modeled as a series of equal structures. These structures are comprised of cylindrical tubes, with the heat transfer fluid flowing inside the tubes and the MH material packed around the outside of the tubes, as indicated in Figure 2. The heat exchange process has been modeled accounting for: (1) a conductive thermal resistance (referred to $\mathrm{U}_{\text {cond) }}$, representing the heat transfer process inside the $\mathrm{MH}$ material; and (2) a convective thermal resistance (referred to as $\mathrm{U}_{\text {conv }}$ ) that represents the heat transfer process occurring inside the tubes. The thermal resistance of the tube wall has been assumed negligible, due to the metallic nature and the thickness of the tube walls that result in a higher conductivity than the MH material thermal conductivity. The conductive thermal resistance $U_{\text {cond }}$, is a function of $D_{\text {in }}$, $\mathrm{D}_{\text {out }}$ and the material thermal conductivity $\mathrm{k}$, as explicitly shown in the Annex.

\footnotetext{
* No hysteresis has been assumed for both the HTMH and LTMH material in the economic analysis, thus single values of the reaction enthalpies (HTMH and LTMH) have been assumed and adopted in the cost evaluation
} 
\{Figure 2\}

The installed cost of the shell and tube heat exchanger has been estimated based on traditional factored method approaches $[17,18]$. The installed cost $\left(\mathrm{C}_{\mathrm{HE}}\right)$ is given by:

$$
\mathrm{C}_{\mathrm{HE}}=\left(\mathrm{C}_{\mathrm{HEHTMH}}+\mathrm{C}_{\mathrm{HELTMH}}\right)\left(1+\mathrm{x}_{\mathrm{HE}}\right)
$$

The first term indicates the heat exchanger Free On Board (FOB) cost of the two MH systems $\left(\mathrm{C}_{\text {Hehtmh }}\right.$ and $\left.\mathrm{C}_{\text {HeLtmH }}\right)$. The second term $\left(1+\mathrm{x}_{\mathrm{HE}}\right)$ indicates the installation costs of the component, including piping, instrumentation, insulation, concrete, as well as the labor needed to install the component. The installation factors $\left(\mathrm{x}_{\mathrm{HE}}\right)$ have been assumed to have the same values for both HTMH and LTMH heat transfer systems.

The first terms (FOB costs) are non-linear functions and depend on the heat transfer area (A), the operating pressures on the tube side $\left(\mathrm{P}_{\mathrm{T}}\right)$ and on the shell side $\left(\mathrm{P}_{\mathrm{S}}\right)^{\S}$, the heat exchanger typology (HETypology) and the heat exchanger constitutive materials (HEMaterial) as indicated in Equations 7-8:

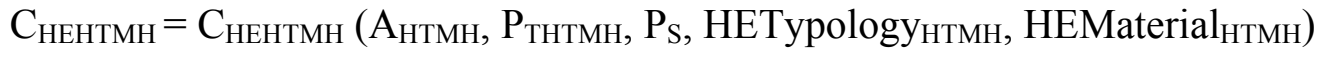

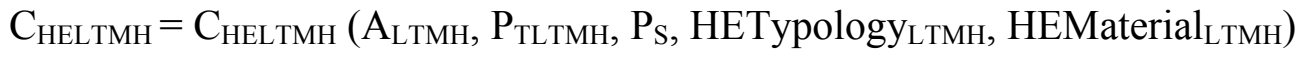

The FOB costs, indicated in Equations 7 and 8, have been assessed using explicit expressions and databases reported in References $[18,19]$ and suitably modified to match the actual system condition and configuration.

ASPEN In-Plant Cost Estimator ${ }^{\circledR}$ has been used to assess the cost of the heat exchangers with suitable modification of the installation cost factors to account for the specific application. More

\footnotetext{
$\S$ The HTMH and LTMH systems works at approximately the same operating pressures, equal to $\mathrm{P}_{\mathrm{S}}$.
} 
detailed cost assessment methodologies, which include specific geometric and constitutive aspects (e.g. tube diameter, tube length, typology and number of baffles) can be used to refine the economic assessment at a successive development of the TES system.

The direct expression of the heat transfer area (A) of the two heat exchangers is given in the Annex. It can be expressed as a function of the plant properties, the MH material thermodynamic and thermal properties, the heat transfer fluid properties and on the heat exchanger geometry, as follows (Equations 9 and 10):

$\mathrm{A}_{\mathrm{HTMH}}=\mathrm{A}_{\mathrm{HTMH}}\left(\mathrm{E}_{\mathrm{th}}, \Delta \mathrm{t}_{\mathrm{s}}, \Delta \mathrm{T}_{\mathrm{HTMH}}, \mathrm{U}_{\text {conv HTMH }}, \mathrm{k}_{\mathrm{HTMH}}, \mathrm{D}_{\text {in HTMH }}, \mathrm{D}_{\text {out HTMH }}\right)$

$\mathrm{A}_{\mathrm{LTMH}}=\mathrm{A}_{\mathrm{LTMH}}\left(\mathrm{E}_{\mathrm{th}}, \Delta \mathrm{t}_{\mathrm{s}}, \Delta \mathrm{H}_{\mathrm{HTMH}}, \Delta \mathrm{H}_{\mathrm{LTMH}}, \Delta \mathrm{T}_{\mathrm{LTMH}}, \mathrm{U}_{\text {conv LTMH }}, \mathrm{k}_{\mathrm{LTMH}}, \mathrm{D}_{\text {in LTMH }}, \mathrm{D}_{\text {out LTMH }}\right)$

From a geometric point of view the heat transfer area can also be expressed as follows (the explicit relationships are reported in the Annex):

$\mathrm{A}_{\mathrm{HTMH}}=\mathrm{A}_{\mathrm{HTMH}}{ }^{\prime}\left(\mathrm{D}_{\text {in HTMH }}, \mathrm{n}_{\mathrm{HTMH}}, \mathrm{L}_{\mathrm{HTMH}}\right)$

$\mathrm{A}_{\mathrm{LTMH}}=\mathrm{A}_{\mathrm{LTMH}}{ }^{\prime}\left(\mathrm{D}_{\mathrm{in} \mathrm{LTMH}}, \mathrm{n}_{\mathrm{LTMH}}, \mathrm{L}_{\mathrm{LTMH}}\right)$

In addition, the characteristic diameters $\mathrm{D}_{\text {out HTMH }}$ and $\mathrm{D}_{\text {out LTMH }}$ are dependent on the volume occupied by the HTMH and LTMH materials as well as on the needed heat transfer area as described in the Annex. They can be expressed using functional relationships as shown in Equation 13 and 14:

$\mathrm{D}_{\text {out HTMH }}=\mathrm{D}_{\text {out HTMH }}\left(\mathrm{D}_{\text {in HTMH }}, \mathrm{n}_{\mathrm{HTMH}}, \mathrm{L}_{\mathrm{HTMH}}, \mathrm{M}_{\mathrm{HTMH}}, \rho_{\mathrm{HTMH}}\right)$

$\mathrm{D}_{\text {out LTMH }}=\mathrm{D}_{\text {out LTMH }}\left(\mathrm{D}_{\text {in LTMH }}, \mathrm{n}_{\text {LTMH }}, \mathrm{L}_{\mathrm{LTMH}}, \mathrm{M}_{\mathrm{LTMH}}, \rho_{\mathrm{LTMH}}\right)$ 
The hydride bed pressure vessel cost has been assessed, adopting the same factored method approach as for the heat transfer system. The pressure vessel FOB cost $\left(\mathrm{C}_{\mathrm{PV}}\right)$ has been evaluated as a function of pressure (P), vessel material (PVMaterial), vessel typology (PVTypology) and the size of the vessel. This was done, depending on the volume of the pressure vessel, using the databases available in Reference [18]. An additional 25\% void volume has been included when estimating the vessel dimensions to allow for the expansion/contraction of the MH material during charging and discharging processes, following best practices [20,21]. The implicit relationships to assess $\mathrm{C}_{\mathrm{PV}}, \mathrm{C}_{\mathrm{PVHTMH}}$ and $\mathrm{C}_{\mathrm{PVLTMH}}$ are shown as Equations 15-17.

$$
\begin{aligned}
& \mathrm{C}_{\mathrm{PV}}=\left(\mathrm{C}_{\mathrm{PVHTMH}}+\mathrm{C}_{\mathrm{PVLTMH}}\right) \\
& \mathrm{C}_{\text {PVHTMH }}=\mathrm{C}_{\text {PVHTMH }}\left(\mathrm{M}_{\text {HTMH }}, \rho_{\text {HTMH }}, \mathrm{P}, \text { PVTypology }{ }_{\mathrm{HTMH}}, \text { PVMaterial }_{\mathrm{HTMH}}\right) \\
& \mathrm{C}_{\text {PVLTMH }}=\mathrm{C}_{\mathrm{PVLTMH}}\left(\mathrm{M}_{\mathrm{LTMH}}, \rho_{\mathrm{LTMH}}, \mathrm{P}, \mathrm{PVTypolog} \mathrm{y}_{\mathrm{LTMH}}, \mathrm{PVMaterial}_{\mathrm{LTMH}}\right)
\end{aligned}
$$

The dependence of the pressure vessel cost on the operating temperature has been assumed negligible, since it does not change the material choice but it only affects the tensile strength of the selected vessel material.

\subsection{The system exergetic efficiency model}

The ideal MH based TES system also needs to achieve the SunShot Initiative technical target, related to the system exergetic efficiency. To evaluate the exergetic efficiency of the MH based TES system a model has been developed at Savannah River National Laboratory. Figure 3 shows the MH storage system interfaced with the high temperature heat exchanger during charging and discharging of thermal energy. Figure 3a shows the heat storage process when the available solar 
thermal power is stored in the MH system. The exergetic input is the thermal exergy available in the high temperature heat transfer fluid $\left(E t h_{c}\right)$. The exergy available in the $\mathrm{MH}$ material system $\left(E_{c}\right)$ is represented by the chemical exergy related to the endothermic hydrogen discharging reaction in the HTMH. Figure $3 \mathrm{~b}$ shows the thermal energy release process with hydrogen charging in the HTMH. In this case the exergetic input is the chemical exergy $\left(\right.$ Ech $\left._{d}\right)$ from the hydrogen charging reaction in the HTMH. The heat transfer fluid exergy represents the thermal exergy available from the TES system $\left(\mathrm{Eth}_{\mathrm{d}}\right)$.

\section{$\{$ Figure 3$\}$}

The exergetic efficiency $(\psi)$ of the system is defined by the product of the exergetic efficiency of the thermal energy storage $\left(\psi_{\mathrm{c}}\right)$ and the exergetic efficiency of the thermal energy release $\left(\psi_{\mathrm{d}}\right)$ :

$$
\psi=\psi_{c} \psi_{d}=\frac{E c h_{c}}{E t h_{c}} \frac{E t h_{d}}{E c h_{d}}
$$

The explicit form of the term Eth $_{\mathrm{c}}$ is reported in the Annex and it can be expressed as a function of the heat transfer fluid (HEFluid), the stored thermal energy $\left(\mathrm{E}_{\mathrm{th}}\right)$, the storage time $\left(\Delta \mathrm{t}_{\mathrm{s}}\right)$, the heat transfer fluid maximum temperature $\left(\mathrm{T}_{1 \mathrm{c}}\right)$, the operating conditions of the HTMH $\left(\mathrm{T}_{\mathrm{HTMH}}\right.$ and $\mathrm{P}$ ) and the $\mathrm{HTMH}$ heat exchanger $\Delta \mathrm{T}_{\mathrm{HTMH}}$ as shown in the following expression:

Eth $_{\mathrm{c}}=\mathrm{Eth}_{\mathrm{c}}\left(\right.$ HEFluid, $\left.\mathrm{E}_{\mathrm{th}}, \Delta \mathrm{t}_{\mathrm{s}}, \mathrm{T}_{1 \mathrm{c}}, \mathrm{T}_{\mathrm{HTMH}}, \Delta \mathrm{T}_{\mathrm{HTMH}}, \mathrm{P}\right)$

The chemical exergy $\left(\mathrm{Ech}_{\mathrm{c}}\right)$ can be expressed as a function of the following parameters (the explicit relationship is reported in the Annex):

$\mathrm{Ech}_{\mathrm{c}}=\mathrm{Ech}_{\mathrm{c}}\left(\mathrm{M}_{\mathrm{HTMH}}, \mathrm{wf}_{\mathrm{HTMH}}, \Delta \mathrm{H}_{\mathrm{HTMHc}}, \Delta \mathrm{S}_{\mathrm{HTMHc}}\right)$ 
The explicit form of the term Eth $\mathrm{d}_{\mathrm{d}}$ is reported in Appendix and it can be expressed as a function of the properties of the heat transfer fluid (HEFluid), the thermal energy to be stored $\left(\mathrm{E}_{\mathrm{th}}\right)$, the storage time, the minimum temperature of the heat transfer fluid $\left(\mathrm{T}_{1 \mathrm{~d}}\right)$, the operating conditions of the HTMH (given by T and P) and the HTMH heat exchanger $\Delta \mathrm{T}$ as reported in the following expression:

Eth $_{\mathrm{d}}=$ Eth $_{\mathrm{d}}\left(\right.$ HEFluid, $\left.\mathrm{E}_{\mathrm{th}}, \Delta \mathrm{t}_{\mathrm{s}}, \mathrm{T}_{\mathrm{ld}}, \mathrm{T}_{\mathrm{HTMH}}, \Delta \mathrm{T}_{\mathrm{HTMH}}, \mathrm{P}\right)$

The chemical exergy $\left(\mathrm{Ech}_{\mathrm{d}}\right)$ can be expressed as a function of the following parameters:

$\operatorname{Ech}_{\mathrm{d}}=\operatorname{Ech}_{\mathrm{d}}\left(\mathrm{M}_{\mathrm{HTMH}}, \mathrm{wf}_{\mathrm{HTMH}}, \Delta \mathrm{H}_{\mathrm{HTMHd}}, \Delta \mathrm{S}_{\mathrm{HTMHd}}\right)$

Additional details on the model principles can be found in Reference [6].

\section{Techno-economic model assumptions}

The techno-economic model described in Section 3 is comprised of 22 equations. The relationships contain 65 variables, including unknown quantities, DOFs, as well as data and constraints given by the operating conditions and targets. In order to simplify and solve the problem, several DOFs have been assumed a priori. The assumed DOFs refer to the thermodynamic and physical properties of the ideal MH materials and the main properties of the pressure vessel and heat exchanger components. The ideal MH material properties have been assessed based on the thermodynamic and physical data available for current MH materials as described in Section 4.1. The assumptions made about the properties of TES heat transfer system properties are described in Section 4.2.

Additional data are related to the solar plant properties and to the targets to be achieved: 
1. The CSP plant property data are (based on typical solar plant data and SunShot targets):

$$
\mathrm{Wel}=100 \mathrm{MW}, \Delta \mathrm{t}_{\mathrm{s}}=13 \text { hours, } \mathrm{PCF}=0.7, \eta_{\mathrm{PP}}=0.45 .
$$

2. The techno-economic performance targets (SunShot targets) are: $\mathrm{C}_{\text {STarget }}=15 \$ / \mathrm{kWhth}$,

$$
\mathrm{T}_{\text {HTMH }}=650^{\circ} \mathrm{C}, \psi_{\text {Target }}=95 \%
$$

\subsection{Metal hydride material properties}

The thermodynamic and physical-chemical properties of the Ideal HTMH materials have been assessed based on the corresponding properties of the currently available HTMH materials. On the basis of the data available in the literature $[13,6]$ the most promising HTMH materials for high temperature solar TES systems are those of $\mathrm{Mg}$ and $\mathrm{Na}$ families (i.e. $\mathrm{Mg}_{2} \mathrm{FeH}_{6}, \mathrm{NaMgH}_{3}$, $\mathrm{NaMgH}_{2} \mathrm{~F}, \mathrm{NaH}$ ) and the Ti and $\mathrm{Ca}$ based hydrides. The properties of these materials are shown in Figures 4-6, based on the information reported in the literature $[9,22,11]$.

Figure 4 shows the theoretical weight capacity of the available HTMH materials working at the temperatures of interest. A profile close to parabolic curve can fit the HTMH data, with a mean square error $\left(\mathrm{R}^{2}\right)$ of 0.62 . Figure 4 shows that the available materials, characterized by reaction enthalpies between $80 \mathrm{~kJ} / \mathrm{molH}_{2}$ and $180 \mathrm{~kJ} / \mathrm{molH}_{2}$, have theoretical weight capacities between about $3 \%$ and about $5 \%$.

\{Figure 4\}

The currently available HTMH materials enthalpy-entropy data are reported in Figure 5; a linear function fits properly the experimental data $\left(\mathrm{R}^{2}=0.896\right)$, with values close to $130 \mathrm{~J} / \mathrm{molH}_{2}-\mathrm{K}$. No hysteresis has been assumed for the MH's because many HTMH materials still lack accurate thermodynamic data on hysteresis. In fact only mean values of reaction enthalpy and reaction entropy for charging and discharging of hydrogen are reported in the literature. With this 
assumption, $\Delta \mathrm{H}_{\mathrm{HTMHc}}=\Delta \mathrm{H}_{\mathrm{HTMHd}}$ and $\Delta \mathrm{S}_{\mathrm{HTMHc}}=\Delta \mathrm{S}_{\mathrm{HTMHd}}$ and the evaluation of the system exergetic efficiency is simplified.

\section{$\{$ Figure 5\}}

Figure 6 shows the HTMH bulk density data (with a compaction to about $70 \%$ of the theoretical crystal density) as a function of the material weight capacity. A typical quadratic profile can properly fit the data $\left(\mathrm{R}^{2}=0.506\right)$, in agreement with considerations and data given in previous publications [23].

\section{$\{$ Figure6\}}

Based on the data reported in Figures 4-6, the properties of the Ideal HTMH materials can be identified. In order to achieve the SunShot performance targets (especially the cost target) the HTMH materials must be paired with inexpensive and high performance LTMH materials as demonstrated by Reference [6].

A comprehensive review of high performance existing LTMH materials to be used in MH based TES systems can be found in Reference [6]. The study concluded that, in order to achieve or closely approach the SunShot economic target, lower cost, non-intermetallic MHs (often referred to as complex hydrides) offer the highest potential to be used as $\mathrm{LTMH}$. $\mathrm{NaAlH}_{4}$ based materials were identified as promising existing LTMH materials. However, due to kinetics limitations, the $\mathrm{NaAlH}_{4} \mathrm{MH}$ requires operating pressures at least on the order of 10-20 bar for the $\mathrm{Na}_{3} \mathrm{AlH}_{6}$ material step [12,24] and on the order of $40-50$ bar for the overall $\mathrm{NaAlH}_{4}$ material [25]. The equilibrium pressure-temperature conditions for the $\mathrm{NaAlH}_{4}$ and $\mathrm{Na}_{3} \mathrm{AlH}_{6}$ materials are reported 
in Figure 7. Consequently, two Ideal Metal Hydride materials, IdMH1 and IdMH2, were identified to be used as HTMH materials, with the following properties:

1. The IdMH1 material is paired with the two step $\mathrm{NaAlH}_{4} \mathrm{LTMH}$ material, requiring operating pressures on the order of at least 40-50 bar. Based on the data shown in Figure 5, a HTMH material with a reaction enthalpy on the order of $98 \mathrm{~kJ} / \mathrm{molH}_{2}$ is appropriate to work at temperatures in the range of $600-700{ }^{\circ} \mathrm{C}$ and corresponding equilibrium pressures of about 20-70 bar (Figure 8).

2. The IdMH2 material is paired with the single step $\mathrm{Na}_{3} \mathrm{AlH}_{6} \mathrm{LTMH}$ material, requiring operating pressures on the order of 10-20 bar. On the basis of data shown in Figure 5, the IdMH2 material, having a reaction enthalpy of $110 \mathrm{~kJ} / \mathrm{molH}_{2}$, is appropriate to operate at temperatures in the range of $650-750{ }^{\circ} \mathrm{C}$ and corresponding equilibrium pressures of 520 bar, as shown in Figure 8.

\{Figure 7\}

\{Figure 8$\}$

The properties of the two selected Ideal MH material systems are summarized in Table 1.

\section{$\{$ Table 1$\}$}

The following assumptions on the MH material cost have been made. The raw LTMH material $\operatorname{cost}\left(\mathrm{C}_{\mathrm{RLTMH}}\right)$ has been assumed equal to $2.7 \$ / \mathrm{kg}$ based on the cost data available for the $\mathrm{NaAlH}_{4}$ material $[6,13]$ with a reduction of about $10 \%$ of the $\mathrm{NaAlH}_{4}$ material cost due to future 
improvements in making large scale quantities of the material. An MH material installation factor $\left(\mathrm{x}_{\mathrm{M}}\right)$ of 0.15 has been assumed for both HTMH and LTMH based on previous experience gained examining automotive and stationary MH storage [21].

\subsection{Metal hydride heat transfer system properties}

After assessing the Ideal MH materials properties, the following additional assumptions (i.e. the DOFs assumed a priori) have been made for the present analysis, regarding the heat transfer and pressure vessel properties.

The heat transfer fluid (HEfluid) is assumed to be air or other inert gases, such as helium. This is due to the fact that these gases are suitable for a wide range of operating temperatures up to 900$1000^{\circ} \mathrm{C}$. Previous studies in the literature report the use of air or inert gases (e.g. helium) as intermediate fluid to exchange the heat between the solar tower and the interfaced equipment of the plant $[26,27]$. The properties of the HEfluid have been evaluated based on NIST database properties [28].

Stainless Steel (SS347) for the HTMH heat exchanger (HEMaterial ${ }_{\text {HTMH }}$ ) and pressure vessel (PVMaterial ${ }_{\mathrm{HTMH}}$ ) system and Aluminum (A16030) for the LTMH heat exchanger (HEMaterial LTMH $_{\text {) and pressure vessel (PVMaterial }}$ LTMH) system have been considered as the current baseline materials. Several references demonstrate the ability of SS347 material to withstand hydrogen environment at temperatures of $650^{\circ} \mathrm{C}$ and pressures (on the order of 350 bar) higher than the current case operating pressures [29]. However, other materials, capable of withstanding higher temperatures can be considered if necessary. A straight tube and shell heat 
exchanger geometry (HETypology) has been assumed for all the MH systems, which employ horizontal pressure vessel configuration (PVTypology).

The convective heat transfer coefficients $\left(\mathrm{U}_{\text {conv }}\right)$ in the tube side of the heat exchangers have been assumed to be $2500 \mathrm{~W} / \mathrm{m}^{2} \mathrm{~K}$ for both the HTMH and LTMH systems. The value is based on the typology of the solar plant, assuming the TES is coupled to a high temperature solar receiver and a steam power plant (or super critical $\mathrm{CO}_{2}$ Brayton power plant). The $\mathrm{HTMH} \mathrm{U}_{\text {conv }}$ is on the same order of the values reported in the literature for high temperature heat transfer fluids, such as helium [27] ${ }^{* *}$. The LTMH $\mathrm{U}_{\text {conv }}$ has been assumed equal to $2500 \mathrm{~W} / \mathrm{m}^{2} \mathrm{~K}$. This value is based on the fact the latent heat from condensing steam is used to heat the LTMH system. Typical condensing steam heat transfer coefficients are on the order of $1000-10000 \mathrm{~W} / \mathrm{m}^{2} \mathrm{~K}$ or even higher.

The HTMH and LTMH material thermal conductivities have been assumed equal to $8 \mathrm{~W} / \mathrm{mK}$. The value has been chosen based on using enhanced thermal conductivity designs, such as adopting finned tube heat exchangers or including ENG in the MH material [30,23].

The $\Delta \mathrm{T}$ in the LTMH heat transfer system has been assumed to be $40 \mathrm{~K}$. The $\Delta \mathrm{T}$ in the HTMH heat transfer system is one of the unknowns of the problem to be evaluated and plays an important role in determining the techno-economic performance of the TES system. Its value has been assumed (i.e. constrained) to be below 40-50 K. Higher $\Delta \mathrm{T}$ values would result in: (1) different operating conditions for the power plant during thermal storage and thermal discharge periods that would reduce excessively the efficiency of the power plant; (2) solar receiver operating temperatures higher than $700{ }^{\circ} \mathrm{C}$ resulting in solar plant operating at conditions

\footnotetext{
${ }^{* *}$ Possible enhancing heat transfer systems (e.g. finned tubes) can be adopted to increase the convective coefficients. The adoption of possible alternative heat transfer fluids (e.g. molten salts) results in increased heat transfer coefficients as well.
} 
different from the SunShot target $\left(650^{\circ} \mathrm{C}\right)$; and (3) reduction of the exergetic efficiency of the TES system.

The heat exchanger tube diameter $\left(D_{\text {in }}\right)$ has been assumed equal to $0.015 \mathrm{~m}$ for both HTMH and LTMH. The number of tubes in the HTMH and LTMH system ( $\mathrm{n}_{\text {HTMH }}$ and $\mathrm{n}_{\text {LTMH }}$ ) has been preliminary assumed based on the desired system layout.

The temperatures of the heat transfer fluid $\mathrm{T}_{\mathrm{ic}}$ and $\mathrm{T}_{\mathrm{id}}$, which are strictly dependent on the value of $\Delta \mathrm{T}$, have been assumed based on the CSP plant configuration and properties.

The installation factors for the heat exchanger system $\left(\mathrm{x}_{\mathrm{HE}}\right)$ have been assumed to be equal to 0.7 based on data reported in literature $[6,21,18]$ and on the heat exchanger size for the current cases.

\section{Ideal metal hydride system performance}

With the assumptions, the targets and the data discussed in Section 4.1 and 4.2 two unknown quantities are present in the set of equations 1-22. The two unknowns are the HTMH raw material cost $\left(\mathrm{C}_{\mathrm{RHTMH}}\right)$ and the HTMH heat transfer system $\Delta \mathrm{T}\left(\Delta \mathrm{T}_{\mathrm{HTMH}}\right)$. Their values identify the Ideal HTMH material TES systems, which can meet or closely approach the SunShot technical and economic targets.

\subsection{Techno-economic performance of the ideal systems}

The IdMH1 and IdMH2 properties (i.e. HTMH raw material cost and $\Delta \mathrm{T}$ of the HTMH heat exchanger) required to meet or closely approach the SunShot cost target (15 \$/kWhth) and exergetic efficiency target $(95 \%)$ are listed in Table 2 . The values of $\mathrm{C}_{\mathrm{RHTMH}}$ and $\Delta \mathrm{T}_{\mathrm{HTMH}}$ have been assessed with the objective of achieving a system specific cost that does not exceed the cost 
target by more than $15 \%$ and a system exergetic efficiency that does not exceed the target by more than $10 \%$ as shown in Table 2 .

\section{$\{$ Table 2\}}

The Pair 1 system requires $\mathrm{C}_{\mathrm{RHTMH}}$ equal to $1.8 \$ / \mathrm{kg}$ and $\Delta \mathrm{T}_{\mathrm{HTMH}}$ equal to $25 \mathrm{~K}$ to achieve a specific cost $\left(\mathrm{C}_{\mathrm{S}}\right)$ of about $17.4 \$ / \mathrm{kWhth}$ and exergetic efficiency $(\psi)$ of about $86.5 \%$. The Pair 2 system requires a lower HTMH raw material cost $(1.4 \$ / \mathrm{kg})$ but a higher $\Delta \mathrm{T}$ in the high temperature heat exchanger $(40 \mathrm{~K})$ to closely approach the techno-economic targets (the Pair 2 specific cost is about $17.3 \$ / \mathrm{kWhth}$ and exergetic efficiency of 93.9\%).

\{Figure 9\}

Figure 9 shows the specific $\operatorname{cost}\left(\mathrm{C}_{\mathrm{S}}\right)$ of the two selected systems, highlighting the contributions of the HTMH and LTMH material cost ('Material HTMH' and 'Material LTMH') and of the HTMH and LTMH heat exchanger and pressure vessel cost ('HE \& PV HTMH' and 'HE \& PV LTMH') on the overall system cost. The first pair is characterized by a high operating pressure that allows the HTMH to be paired with a high capacity LTMH system $\left(\mathrm{NaAlH}_{4}\right)$. This reduces the cost of the LTMH system that represents about $48 \%$ of the overall system cost. Consequently the HTMH system influences the overall cost for about $52 \%$. The high operating pressure makes the HTMH heat exchanger and pressure vessel related cost represent about $30 \%$ of the overall system cost. The second MH pair operates at lower pressure, which allows the IdMH2 material to be paired with only a lower capacity LTMH material $\left(\mathrm{Na}_{3} \mathrm{AlH}_{6}\right)$. This is reflected in the cost contributions depicted in Figure 9 for the second pair. The influence of the LTMH system on the overall cost is about $61 \%$. The increase in the relative cost of the LTMH system is especially due to the lower LTMH weight capacity as compared to the corresponding LTMH of the first system. 
However the lower operating pressure reduces the cost of the HTMH heat exchanger and pressure vessel resulting in a contribution to the overall system cost of only approximately $21.5 \%$.

As shown in Reference [6], all the MH based TES systems easily exceed the volumetric energy density SunShot target $\left(25 \mathrm{kWhth} / \mathrm{m}^{3}\right)$, with values on the order of ten times higher than the target. The results obtained for the two ideal systems (IdMH1 and IdMH2), including HTMH and LTMH materials as well as $10 \mathrm{wt} \%$ ENG included in the two systems, demonstrate their ability to reach volumetric capacities on the order of $297 \mathrm{kWhth} / \mathrm{m}^{3}$ and $255 \mathrm{kWhth} / \mathrm{m}^{3}$ respectively.

\subsection{Ideal system performance sensitivity analyses}

On the basis of the results obtained, several sensitivity analyses were performed for the two ideal MH systems. The influence of the most relevant and distinguishing properties of the solar plant on cost and on exergetic efficiency of the TES system has been evaluated with results shown in Figures 10-13. The sensitivity of the specific cost of the TES system has been assessed varying: (1) HTMH and LTMH material thermodynamic and physical properties (e.g. bulk density, reaction enthalpy, weight capacity, operating pressure); (2) cost factors and economic properties (e.g. raw MH material cost, cost of heat exchanger and pressure vessel); (3) heat transfer system properties (e.g. material thermal conductivity, convective heat transfer coefficient, heat exchanger mean temperature difference); and (4) overall solar plant characteristics (e.g. plant capacity factor and storage time). The sensitivity of the exergetic efficiency of the TES system has been assessed varying: (1) HTMH material properties (i.e. reaction enthalpy and reaction entropy); (2) HTMH heat exchanger properties (i.e. mean temperature difference, $\Delta \mathrm{T}$ ). Each parameter varies (maintaining the baseline values of the other quantities) between minimum and 
maximum values indicated in the cost range included in Figures 10-13 with the corresponding cost and exergetic efficiency variation reported as bar charts. In particular, the $\mathrm{C}_{\mathrm{RHTMH}}$ values vary between a minimum of about $1 \$ / \mathrm{kg}$ and a maximum of $4 \$ / \mathrm{kg}$. In general only HTMH's that have this raw material cost range have been demonstrated to have the potential to meet or approach the SunShot target [6]. Another relevant TES system property that affects the performance of the TES is the $\Delta \mathrm{T}$ of the HTMH. The sensitivity analyses have been carried out assuming a range between about $15 \mathrm{~K}$ to about $50 \mathrm{~K}$ according to the considerations reported in Section 4.2. The range of variation of the HTMH material thermodynamic and structural properties has been assumed based on the data shown in Figures 4-6 and on the typical values of the HTMH materials [6]. The range of variation of the LTMH thermodynamic and structural properties has been assumed based on the values of $\mathrm{NaAlH}_{4}$ and $\mathrm{Na}_{3} \mathrm{AlH}_{6}$ materials and on the data available for other possible LTMH materials [6]. The cost range of the LTMH material has been assumed between $2 \$ / \mathrm{kg}$ and $4 \$ / \mathrm{kg}$, where the current $\mathrm{NaAlH}_{4}$ raw material cost is on the order of 3-3.5 $\$ / \mathrm{kg}$ [6]. A material compaction up to about $80 \%$ of the crystal density (i.e. 1200 $\mathrm{kg} / \mathrm{m}^{3}$ ) has been assumed based on compaction data available from General Motors $®$ for pelletized $\mathrm{NaAlH}_{4}$ based materials [30,23]. A possible LTMH reaction enthalpy and weight capacity variation from about $25 \mathrm{~kJ} / \mathrm{molH}_{2}$ to $60 \mathrm{~kJ} / \mathrm{molH}_{2}$ and from $2 \%$ to $4.5 \%$ has been considered respectively, based on the typical LTMH values $[6,13]$ and on the $\mathrm{NaAlH}_{4}$ material properties. The operating pressure has been varied with values up to 40 bar (for the IdMH1 system) and to 60 bar (for the IdMH2 system). The HTMH thermal conductivity baseline value is equal to $8 \mathrm{~W} / \mathrm{mK}$. The variation of the HTMH thermal conductivity has been assumed to be in the range $4-10 \mathrm{~W} / \mathrm{mK}$. The assumptions is based on varying the material properties using additives and possible inclusion of different thermal conductivity enhancement systems. The 
HTMH convective heat transfer coefficient varies between $600 \mathrm{~W} / \mathrm{m}^{2} \mathrm{~K}$ to $4000 \mathrm{~W} / \mathrm{m}^{2} \mathrm{~K}$ (the baseline value is equal to $2500 \mathrm{~W} / \mathrm{m}^{2} \mathrm{~K}$ ). This value strongly depends on the adopted fluid to transfer heat between the TES system and the solar plant. Values reported in literature for molten salt fluids [31] or for gaseous heat transfer fluids [27] are on the order of those assumed in the current analysis. The LTMH convective heat transfer coefficient varies between $2500 \mathrm{~W} / \mathrm{m}^{2} \mathrm{~K}$ (baseline value) to $10000 \mathrm{~W} / \mathrm{m}^{2} \mathrm{~K}$. The assumed range is based on the fact that the heat transfer fluid is likely condensing steam, with typical heat transfer coefficient values on the order of $1000-10000 \mathrm{~W} / \mathrm{m}^{2}-\mathrm{K}$. The sensitivity of the TES specific cost to the cost variation of the heat exchanger and pressure vessel cost (HE\&PV) has also been assessed for both the LTMH and HTMH systems assuming a variation $\pm 40 \%$ of the baseline HE\&PV cost. Such a variation can be caused by the adoption of different tube and vessel materials for both HTMH and LTMH system or by operating at different pressures or by considering different vessel configurations and typologies. Figures 10 and 11 show the results of the techno-economic sensitivity analyses for the IdMH1 system. The baseline case parameters for the IdMH1-NaAlH 4 system are: $\mathrm{C}_{\mathrm{RHTMH}}=$ $1.8 \$ / \mathrm{kg}, \Delta \mathrm{T}_{\mathrm{HTMH}}=25 \mathrm{~K}, \mathrm{C}_{\mathrm{RLTMH}}=2.7 \$ / \mathrm{kg}, \Delta \mathrm{T}_{\mathrm{LTMH}}=40 \mathrm{~K}, \rho_{\mathrm{HTMH}}=1400 \mathrm{~kg} / \mathrm{m}^{3}, \rho_{\mathrm{LTMH}}=900$ $\mathrm{kg} / \mathrm{m}^{3}, \Delta \mathrm{H}_{\mathrm{HTMH}}=98 \mathrm{~kJ} / \mathrm{molH}_{2}, \Delta \mathrm{S}_{\mathrm{HTMH}}=133 \mathrm{~J} / \mathrm{mol}-\mathrm{K}, \Delta \mathrm{H}_{\mathrm{LTMH}}=40 \mathrm{~kJ} / \mathrm{molH}_{2}, \mathrm{wf}_{\mathrm{HTMH}}=3.8 \%$, $\mathrm{wf}_{\mathrm{LTMH}}=4 \%, \mathrm{P}=40$ bar, $\mathrm{k}_{\text {HTMH }}=8 \mathrm{~W} / \mathrm{mK}, \mathrm{U}_{\text {convHTMH }}=2500 \mathrm{~W} / \mathrm{m}^{2} \mathrm{~K}, \mathrm{U}_{\text {convLTMH }}=2500$ $\mathrm{W} / \mathrm{m}^{2} \mathrm{~K}, \mathrm{PCF}=0.7$ (with a storage time of 13 hours).

$\{$ Figure 10$\}$

The economic performance of the $\mathrm{IdMH}_{1}-\mathrm{NaAlH}_{4}$ system is strongly affected by the raw $\mathrm{MH}$ material costs. An increase of the HTMH cost from $1.8 \$ / \mathrm{kg}$ to $4 \$ / \mathrm{kg}$ results in an increase of the TES system specific cost of about $25 \%$, while an increase of the LTMH cost of about $48 \%$ (up to $4 \$ / \mathrm{kg}$ ) results in an increase of the total TES cost of about $15 \%$. Another relevant 
property affecting the cost of the system is the $\mathrm{MH}$ weight capacity. A reduction of about $50 \%$ of the HTMH wf results in an increase of the TES cost of about $23 \%$, while a reduction of the LTMH wf of about $42 \%$ determines a cost increase of almost $19 \%$. The high operating pressure of the IdMH1 system makes the cost of the pressure vessel and heat exchangers (HE\&PV) strongly influence the overall system cost. A variation of this cost of $40 \%$ (for HTMH system) results in a significant variation of the overall system cost for about $12 \%$. Figure 10 highlights that the HTMH reaction enthalpy, which identifies the amount of hydrogen to be moved between the HTMH and LTMH materials, strongly influences the TES cost. An increase of $7 \%$ of the HTMH reaction enthalpy results in a decrease of the specific cost by about $5 \%$, while a decrease of the reaction enthalpy of about $13 \%$ leads to an increase of the specific cost of about $10 \%$. In addition, the material property plays a major role in determining the exergetic efficiency of the system. Based on the existing data for the current available $\mathrm{HTMH}$ materials, the $\Delta \mathrm{H}_{\mathrm{HTMH}}$ has been varied between $85 \mathrm{~kJ} / \mathrm{molH}_{2}$ and $105 \mathrm{~kJ} / \mathrm{molH}_{2}$, with exergetic efficiency results given in Figure 11. A variation of about $13 \%$ of the HTMH reaction enthalpy results in a variation of the exergetic efficiency of the TES system of about $22 \%$. The other parameter significantly affecting both the cost and the exergetic efficiency of the TES system (especially the cost of the system) is $\Delta \mathrm{T}_{\mathrm{HTMH}}$. Designing the $\mathrm{HTMH}$ heat transfer system with $\Delta \mathrm{T}$ equal to $50 \mathrm{~K}$ (rather than $25 \mathrm{~K}$ ) results in a cost reduction of about $8 \%$.

\section{$\{$ Figure 11\}}

Figures 12 and 13 show the results of the techno-economic sensitivity analyses for the IdMH2 system. The baseline case parameters for the $\mathrm{IdMH}_{2}-\mathrm{Na}_{3} \mathrm{AlH}_{6}$ system are: $\mathrm{C}_{\mathrm{RHTMH}}=1.4 \$ \mathrm{~kg}$, $\Delta \mathrm{T}_{\mathrm{HTMH}}=40 \mathrm{~K}, \mathrm{C}_{\mathrm{RLTMH}}=2.7 \$ / \mathrm{kg}, \Delta \mathrm{T}_{\mathrm{LTMH}}=40 \mathrm{~K}, \rho_{\mathrm{HTMH}}=1600 \mathrm{~kg} / \mathrm{m}^{3}, \rho_{\mathrm{LTMH}}=900 \mathrm{~kg} / \mathrm{m}^{3}$, $\Delta \mathrm{H}_{\mathrm{HTMH}}=110 \mathrm{~kJ} / \mathrm{molH}_{2}, \Delta \mathrm{S}_{\mathrm{HTMH}}=131 \mathrm{~J} / \mathrm{mol}-\mathrm{K}, \Delta \mathrm{H}_{\mathrm{LTMH}}=47 \mathrm{~kJ} / \mathrm{molH}_{2}, \mathrm{wf}_{\mathrm{HTMH}}=3.5 \%$, 
$\mathrm{wf}_{\mathrm{LTMH}}=2.7 \%, \mathrm{P}=15 \mathrm{bar}, \mathrm{k}_{\text {HTMH }}=8 \mathrm{~W} / \mathrm{mK}, \mathrm{U}_{\text {convHTMH }}=2500 \mathrm{~W} / \mathrm{m}^{2} \mathrm{~K}, \mathrm{U}_{\text {convLTMH }}=2500$

$\mathrm{W} / \mathrm{m}^{2} \mathrm{~K}, \mathrm{PCF}=0.7$ (with a storage time of 13 hours).

$\{$ Figure 12\}

$\{$ Figure 13\}

The economic performance of the IdMH2- $\mathrm{NaAlH}_{4}$ system is significantly affected by the HTMH and LTMH raw material costs. An increase of the HTMH cost from $1.4 \$ / \mathrm{kg}$ to $4 \$ / \mathrm{kg}$ results in an increase of the TES system specific cost of about $31 \%$, while an increase of the LTMH cost of about $48 \%$ results in an increase of the total TES cost of about $21 \%$ as demonstrated by the results reported in Figure 12. A decrease of the LTMH material cost down to $2 \$ / \mathrm{kg}$ makes the TES closely approach the cost target of $15 \$ / \mathrm{kWhth}$. Figure 12 shows that the HTMH and LTMH weight capacity strongly influences the cost of the system. A reduction of about $29 \%$ of the HTMH wf results in an increase of the TES cost of about $10 \%$, while a reduction of the LTMH wf of about $26 \%$ leads to a cost increase of almost $20 \%$. The moderate operating pressure of the IdMH2 system reduces the cost of the pressure vessel and heat exchangers and makes them influence the overall system cost less than the IdMH1 system. A variation of the HTMH HE\&PV cost of $40 \%$ results in a variation of the overall system cost of about $8.5 \%$. The HTMH reaction enthalpy strongly affects the TES system cost as well as the exergetic efficiency. An increase of $4.5 \%$ of the HTMH reaction enthalpy results in a decrease of the specific cost by approximately 5\%. Based on the existing data for the current available HTMH materials, the $\Delta \mathrm{H}_{\text {Нтмн }}$ has been varied between $95 \mathrm{~kJ} / \mathrm{molH}_{2}$ and $115 \mathrm{~kJ} / \mathrm{molH}_{2}$, with the corresponding exergetic efficiency results reported in Figure 13. A variation of about $4.5 \%$ of the HTMH 
reaction enthalpy results in a variation of the exergetic efficiency of the TES system of about $2 \%$ making the system exceed the target of $95 \%$.

\subsection{Metal hydride TES outlook}

The performance of the two ideal MH systems (IdMH1 and IdMH2) has been compared with that of the most promising MH materials reported in Table 3.

\section{$\{$ Table 3$\}$}

The first material couple $\left(\mathrm{NaMgH}_{3}-\mathrm{NaAlH}_{4}\right)$ [6] shows a cost almost double than that of the ideal systems and an exergetic efficiency approximately $14 \%$ lower than the target of $95 \%$. In addition, the $\mathrm{HTMH}$ material operating temperature is lower than the target of $650{ }^{\circ} \mathrm{C}$. The second couple $\left(\mathrm{NaMgH}_{2} \mathrm{~F}-\mathrm{Na}_{3} \mathrm{AlH}_{6}\right)$ is based on a new material developed by Curtin University with techno-economic analysis carried out within SunShot program by the Savannah River National Laboratory in conjunction with Curtin University $[12,11]$. The couple shows high potential to approach the SunShot targets, but still requires HTMH material development and further modifications in order to achieve higher stability and to increase its operating temperature [12]. The main limitation of the third couple $\left(\mathrm{TiH}_{2}-\mathrm{TiFeH}_{2}\right)[6]$ is due to the cost of the system, constituted by MH materials that are too expensive to approach the target. Additional material development is also needed in order to prevent the formation of different Ti hydride material phases during hydrogenation and dehydrogenation. The fourth couple $\left(\mathrm{CaH}_{2}-\mathrm{TiFeH}_{2}\right)$ reported in Table 3 [6] shows good potential in approaching the targets. Ca based HTMH materials are promising and appealing candidate MH's to meet the SunShot targets. However, due to severe corrosion issues (mainly due to melting of $\mathrm{CaH}_{2} / \mathrm{Ca}$ material at the current operating conditions) 
Ca hydride material modification is needed in order to overcome corrosion issues and make the system a practical TES.

\section{Summary and conclusions}

A simplified techno-economic model has been established and described in the paper, with the aim of assessing the performance of CSP solar thermal energy storage systems based on metal hydride materials. The analysis focused on the evaluation of the technical and economic properties of the ideal metal hydride systems (i.e. the systems being able to achieve, or closely approach, the DOE SunShot targets, in terms of system cost, exergetic efficiency, volumetric density and operating temperatures). On the basis of the thermodynamic and structural data of the currently available metal hydrides, two ideal metal hydride systems were identified as being able to closely approach the techno-economic targets. The first system operates at temperatures on the order of $600-700{ }^{\circ} \mathrm{C}$ and at pressures on the order of 50 bar. To meet the cost targets the system needs to utilize a high temperature metal hydride material that costs about $1.8 \$ / \mathrm{kg}$. In addition, the heat exchanger system (based on the shell and tube configuration) needs to be designed for a mean temperature difference of approximately $25{ }^{\circ} \mathrm{C}$ in order to approach both the economic and exergetic efficiency targets. The second system can operate at slightly higher temperatures (on the order of $650-750^{\circ} \mathrm{C}$ ) and lower pressures (on the order of 20 bar). To meet the cost targets the second system needs a high temperature metal hydride material that costs approximately $1.4 \$ / \mathrm{kg}$. The heat exchanger system (based on the shell and tube configuration) can be designed for a higher mean temperature difference (approximately $40{ }^{\circ} \mathrm{C}$ ) in order to 
approach the targets. Selected sensitivity analyses have been carried out to evaluate the influence of the most distinguishing parameters on the technical and economic performance of the ideal metal hydride based thermal energy storage system. Results of the analysis showed that the raw material costs, the material weight capacities and the high temperature metal hydride reaction enthalpies are the parameters that have the most influence on the cost and exergetic efficiency of the storage system. A quick comparison with some of the most promising metal hydrides for solar thermal storage application has also been carried out, demonstrating that selected metal hydrides have the potential to approach the SunShot targets. Materials reported in the paper show good potential to achieve the cost and exergetic efficiency targets, but they require additional material development in order to make the hydride system a practical TES concept. In particular, Ca-based HTMH materials, with suitable material modifications, show the highest potential to meet the techno-economic targets and represent the best candidates for a high efficiency and low cost TES system.

\section{Acknowledgments}

This work was performed as part of the DOE EERE SunShot Initiative. Dr L. Irwin and Dr A. Schultz, Sunshot Project Managers, are acknowledged in appreciation for their help and direction.

\section{Annex}

1. Economic model 
The overall thermal energy stored in the TES system $\left(\mathrm{E}_{\mathrm{th}}\right)$ is:

$$
\mathrm{E}_{\mathrm{th}}=\left(\mathrm{W}_{\mathrm{el}} \bullet \Delta \mathrm{t}_{\mathrm{s}}\right) /\left(\eta_{\mathrm{PP}} \cdot \mathrm{PCF}\right)
$$

$\mathrm{W}_{\mathrm{el}}$ is the average electric power generated by the power plant throughout the year. $\Delta \mathrm{t}_{\mathrm{s}}$ is the storage time, $\eta_{\mathrm{PP}}$ is the power plant efficiency and the PCF is the plant capacity factor.

The cost of the MH material has been evaluated based on the $\mathrm{MH}$ material weight. The hydrogen mass to be stored (i.e. moved from the HTMH to the LTMH and vice versa) can be expressed as follows:

$$
\mathrm{M}_{\mathrm{H} 2}=\left(\mathrm{W}_{\mathrm{el}} \bullet \Delta \mathrm{t}_{\mathrm{s}}\right) /\left(\eta_{\mathrm{PP}} \bullet \mathrm{PCF} \bullet \Delta \mathrm{H}_{\mathrm{HTMH}}\right)
$$

Consequently the mass of the HTMH and LTMH material can be assessed, once the weight capacity of the MH material is known. The HTMH mass and volume are:

$$
\begin{aligned}
& \mathrm{M}_{\mathrm{HTMH}}=\mathrm{M}_{\mathrm{H} 2} / \mathrm{wf}_{\mathrm{HTMH}} \\
& \mathrm{V}_{\mathrm{HTMH}}=\mathrm{M}_{\mathrm{HTMH}} / \rho_{\mathrm{HTMH}}
\end{aligned}
$$

The LTMH material mass and volume are:

$$
\begin{aligned}
& \mathrm{M}_{\mathrm{LTMH}}=\mathrm{M}_{\mathrm{H} 2} / \mathrm{wf}_{\mathrm{LTMH}} \\
& \mathrm{V}_{\mathrm{LTMH}}=\mathrm{M}_{\mathrm{LTMH}} / \rho_{\mathrm{LTMH}}
\end{aligned}
$$


The conductive thermal resistance, given the heat exchanger configuration reported in Figure 2, is expressed as $\mathrm{U}_{\text {cond }}$ :

$\frac{1}{U_{\text {cond }}}=D_{\text {in }} \frac{\ln \frac{D_{\text {out }}}{D_{\text {in }}}}{2 k}$

The thermal power $\left(\mathrm{W}_{\text {th }}\right)$ to be exchanged with the TES system can be expressed as:

$\mathrm{W}_{\mathrm{th}}=\mathrm{E}_{\mathrm{th}} / \Delta \mathrm{t}_{\mathrm{s}}$

The same quantity $\left(\mathrm{W}_{\text {th }}\right.$ ) can be expressed in terms of heat transfer balance (assuming negligible the temperature difference in the conduction process across the tube wall) for both the HTMH and LTMH system, as given below:

$W_{\text {th }}=\frac{1}{\left(\frac{1}{U_{\text {cond }}}+\frac{1}{U_{\text {conv }}}\right)} A \cdot \Delta T$

with $\mathrm{A}\left(\mathrm{m}^{2}\right)$ being the heat transfer area and $\Delta T(\mathrm{~K})$ being the corrected mean temperature difference in the heat exchanger.

The heat transfer area can be expressed (geometrically) as:

$A=n \pi D_{i n} L$

with $\mathrm{n}$ being the number of tubes and $\mathrm{L}(\mathrm{m})$ the length of tubes.

In addition, the total volume of the $\mathrm{MH}$ system $\left(\mathrm{V}_{\text {tot }}\right)$ can be expressed as the sum of the $\mathrm{MH}$ volume $\left(\mathrm{V}_{\mathrm{MH}}\right)$ and the volume occupied by the heat exchanger tubes. The total volume can also be expressed in terms of tank internal diameter $\left(D_{\text {vessel }}\right)$ as shown in the following equations. 
$V_{\text {tot }}=V_{M H}+\left(\frac{\pi D_{i n}^{2}}{4} n \cdot L\right)=\frac{\pi D_{\text {vessel }}^{2}}{4} L$

The tank internal diameter $\left(\mathrm{D}_{\text {vessel }}\right)$ can be easily related to the diameter $\mathrm{D}_{\text {out }}$ depending on the geometry of the system.

\section{Exergetic efficiency model}

The exergetic efficiency model equations are briefly summarized below. More details on the model can be found in Reference [6].

With reference to Figure 3 and Equations 18-22, the thermal exergy during the heat storage process $\left(E_{\mathrm{c}}\right)$ is expressed as:

$E t h_{c}=\dot{m}_{c} \Delta t_{s}\left(h_{o c}-h_{i c}-T_{0}\left(s_{o c}-s_{i c}\right)\right)$

with $m_{c}$ being the heat transfer fluid mass flow rate and with $\mathrm{h}_{\mathrm{oc}}\left(\right.$ and $\left.\mathrm{s}_{\mathrm{oc}}\right)$ and $\mathrm{h}_{\mathrm{ic}}\left(\right.$ and $\left.\mathrm{s}_{\mathrm{ic}}\right)$ being the enthalpy (and entropy) at points oc and ic respectively and $\mathrm{T}_{0}(\mathrm{~K})$ being the reference temperature.

Thus $\mathrm{Eth}_{\mathrm{c}}$ is a function of the heat transfer fluid, $\mathrm{E}_{\mathrm{th}}, \Delta \mathrm{t}_{\mathrm{s}}, \mathrm{T}_{\mathrm{ic}}, \mathrm{T}_{\mathrm{HTMH}}, \Delta \mathrm{T}_{\mathrm{HTMH}}$ and operating pressure, which determine the terms reported in Equation a12.

The chemical exergy from the heat storage $\left(\mathrm{Ech}_{\mathrm{c}}\right)$ is expressed as:

$E c h_{c}=\frac{M_{H 2}}{0.002}\left(\Delta H_{c}-T_{0} \Delta S_{c}\right)$

with $\Delta \mathrm{H}_{\mathrm{c}}$ and $\Delta \mathrm{S}_{\mathrm{c}}$ representing the reaction enthalpy and entropy of the HTMH during thermal energy storage. 
The thermal exergy during the heat release $\left(E t h_{d}\right)$ is expressed as:

$E t h_{d}=\dot{m}_{d} \Delta t_{s}\left(h_{o d}-h_{i d}-T_{0}\left(s_{o d}-s_{i d}\right)\right)$

with $\dot{m}_{d}$ representing the heat transfer fluid mass flow rate and with $\mathrm{h}_{\mathrm{od}}$ (and $\left.\mathrm{s}_{\mathrm{od}}\right)$ and $\mathrm{h}_{1 \mathrm{~d}}$ (and $\mathrm{S}_{\mathrm{id}}$ ) representing the enthalpy (and entropy) at points od and id respectively and $\mathrm{T}_{0}(\mathrm{~K})$ being the reference temperature.

Thus $E_{\mathrm{d}}$ is a function of the heat transfer fluid, $\mathrm{E}_{\mathrm{th}}, \Delta \mathrm{t}_{\mathrm{s}}, \mathrm{T}_{\mathrm{id}}, \mathrm{T}_{\mathrm{HTMH}}, \Delta \mathrm{T}_{\mathrm{HTMH}}$ and operating pressure, which determine the terms indicated in Equation a14.

The chemical exergy from the heat release $\left(\mathrm{Ech}_{\mathrm{d}}\right)$ is expressed as:

$E c h_{d}=\frac{M_{H 2}}{0.002}\left(\Delta H_{d}-T_{0} \Delta S_{d}\right)$

with $\Delta \mathrm{H}_{\mathrm{d}}$ and $\Delta \mathrm{S}_{\mathrm{d}}$ representing the reaction enthalpy and entropy of the HTMH during thermal energy release.

\section{References}

[1] Website: http://www.nrel.gov/csp/pdfs/48658.pdf. [accessed April 2015]

[2] Gil A, Medrano M, Martorell I, Lazaro A, Dolado P, Zalba B, et al. State of the art on high temperature thermal energy storage for power generation. Part 1 - Concepts, materials and modellization. Renewable and Sustainable Energy Reviews 2010;14:31-55. 
[3] Stekli J, Irwin L, Pitchumani R. Technical challenges and opportunities for concentrating solar power with thermal energy storage. Journal of Thermal Science and Engineering Applications 2013;5:021011-1-12.

[4] Dominguez R, Baringo L, Conejo A. Optimal strategy for a concentrating solar power plant. Applied Energy 2012;98:316-325.

[5] Denholm P, Hand M. Grid Flexibility and Storage Required to Achieve Very High Penetration of Variable Renewable Electricity. Energy Policy 2011;39(3):1817-1830.

[6] Corgnale C, Hardy BJ, Motyka T, Zidan R, Teprovich J, Peters B. Screening analysis of metal hydride based thermal energy storage systems for concentrating solar power plants. Renew Sustain Energy Rev 2014;38:821-833.

[7] Caldwell RT, McDonald JW, Pietsch A. Solar-energy receiver with lithium-hydride heat storage. Solar Energy 1965;9:48-60.

[8] Bogdanovic B, Hofmann H, Neuy A, Reiser A, Schlichte K. Ni-doped versus undoped Mg$\mathrm{MgH}$ materials for high temperature heat or hydrogen storage. Journal of Alloys and Compounds 1999;292:57-71.

[9] Reiser A, Bogdanovic B, Schlichte K. The application of Mg-based metal-hydrides as heat energy storage systems. Int J Hydrogen Energy 2000;25:425-430.

[10] Sheppard D, Paskevicius M, Buckley C. Thermodynamics of hydrogen desorption from $\mathrm{NaMgH} 3$ and its application as a solar heat storage medium. Chem Mater 2011;23:4298-4300.

[11] Sheppard D, Corgnale C, Hardy B, Motyka T, Zidan R, Paskevicious M, et al. Hydriding characteristics of $\mathrm{NaMgH} 2 \mathrm{~F}$ with preliminary technical and cost evaluation of magnesium-based 
metal hydride materials for concentrating solar power thermal storage. RSC Advances 2014;51(4):26552-62.

[12] Ward P, Corgnale C, Teprovich J, Motyka T, Hardy B, Peters B et al. High performance metal hydride based thermal energy storage systems for concentrating solar power applications" Journal of Alloys and Compounds 2015;645(1):S374-S378.

[13] Harries D, Paskevicius M, Sheppard D, Price T, Buckley C. Concentrating solar thermal heat storage using metal hydrides. Proceedings of the IEEE 2012;100:539-549.

[14] DOE ARPA-E. High Energy Advanced Thermal Storage. DOE-FOA-0000471, 2011, available at https://arpa-e-foa.energy.gov/FileContent.aspx?FileID=79a5de09-8bfd-4590-9cb4e42578248d90 [accessed April 2014].

[15] DOE SunShot. SunShot National Laboratory Multiyear Partnership (SuNLaMP) call for proposal FY2016-FY2018. Year 2015.

[16] DOE SunShot. SunShot Vision Study - Chapter 5. February 2012.

[17] Guthrie KM. Data and Techniques For Preliminary Capital Cost Estimating. Chemical Eng Prog 1969;114-142.

[18] Douglas E. Industrial Chemical Process Design. McGrw-Hill Professional Engineering, 2003.

[19] Aspentech websites: http://www.aspentech.com/products/aspen-icarus-projectmanager.aspx; http://www.aspentech.com/products/aspen-kbase.aspx [accessed April 2015]. 
[20] Corgnale C, Hardy B, Anton D. Structural analysis of metal hydride-based hybrid hydrogen storage systems. Int J Hydrog Energy 2012;37(19):14223-33.

[21] Motyka T. Savannah River National Laboratory Regenerative Fuel Cell Project. SRNL-STI2008-00388, Nov. 11, 2008.

[22] Mueller W, Blackledge J, Libowitz G. Metal Hydrides. 1968 Academic Press New York and London.

[23] Pasini JM, Corgnale C, van Hassel B, Motyka T, Kumar S, Simmons K. Metal hydride material requirements for automotive hydrogen storage systems. Int J Hydrogen Energy 2013;38(23):9755-9765.

[24] Urbanczyk R, Peinecke K, Felderhoff M, Hauschild K, Kersten W, Peil S, et al. Aluminum alloy based hydrogen storage tank operated with sodium aluminum hexahydride Na3AlH6. Int J Hydrog Energy 2014;39(30):17118-28.

[25] Hardy BJ, Anton DL. Hierarchical methodology for modeling hydrogen storage systems. Part II: Detailed models. Int J Hydrogen Energy 2009;(34):2992-3004.

[26] Website:

http://www.dlr.de/Portaldata/41/Resources/dokumente/institut/system/publications/Concentratin g_Solar_Power_Part_1.pdf [accessed January 2015].

[27] Corgnale C, Summers W. Solar hydrogen production by the Hybrid Sulfur process. Int J Hydrogen Energy 2011;36(18):11604-19.

[28] Website: http://webbook.nist.gov/chemistry/fluid/ [accessed May 2015]. 
[29] Somerday BP, San Marchi C. Technical reference on hydrogen compatibility of materials Austenitic Steels: 300-series Stainless Alloys. Sandia National Laboratory SAND2008-1163, 2008.

[30] Corgnale C, Hardy BJ, Tamburello DA, Garrison SL, Anton DL. Acceptability envelope for metal hydride-based hydrogen storage systems. Int J Hydrogen Energy 2012;37:2812-24.

[31] Williams DF. Assessment of candidate molten salt coolants for the NGNP-NHI heattransfer loop. Oak Ridge National Laboratory, ORNL/TM-2006/69, June 2006. 